\title{
Colaboração entre estado e municípios para a alfabetização de crianças na idade certa no Ceará
}

Joana Buarque de Gusmão *

Vanda Mendes Ribeiro**

* Mestre em Educação pela Faculdade de Educação da Universidade de São Paulo (FE-USP).

** Mestre em Sociologia pela Unicamp e doutoranda em Educação pela FE-USP. Bolsista Capes.

\section{RESUMO}

O artigo tem por objetivo apresentar o Programa Alfabetização na Idade Certa (PAIC), desenvolvido sob regime de colaboração entre o Estado do Ceará e seus municípios, com apoio do Unicef. A principal finalidade do Programa é alfabetizar todos os alunos das redes públicas de ensino até os sete anos de idade. Com base na apresentação do Paic, o artigo procura descrever seus principais processos, compartilhar seus resultados, elencar os desafios para sua continuidade, bem como, especialmente, destacar o que se considera ser um padrão de cooperação entre estado e municípios com vistas à melhoria da qualidade educacional.

PALAVRAS-CHAVE

Regime de colaboração. Política educacional. Alfabetização. 


\section{APRESENTAÇÃO}

A adoção de estratégias para operacionalizar o regime de colaboração entre os entes federados no País visando ampliar o direito à educação é temática que tem ganhado destaque (ARAÚJO, 2010). Expressa princípio previsto na Constituição de 1988; foi um dos grandes pontos de debate na Conferência Nacional de Educação realizada em 2010 e está explicitada no artigo 7ํ do projeto de lei enviado pelo governo federal ao Congresso Nacional em dezembro de 2010, com o objetivo de regulamentar o Plano Nacional de Educação (PNE):

Art. $7^{\circ}$. A consecução das metas do PNE - 2011/2020 e a implementação das estratégias deverão ser realizadas em regime de colaboração entre a União, os Estados, o Distrito Federal e os Municípios. (CÂMARA DOS DEPUTADOS, 2010)

O Programa Alfabetização na Idade Certa é uma política de cooperação entre estado e municípios promovida pelo governo do Ceará, em parceria com o Fundo das Nações Unidas para a Infância (UNICEF) e instituições da sociedade civil, com apoio do governo federal, cujo objetivo é alfabetizar todos os alunos das redes públicas de ensino do estado até os sete anos de idade. Com essa finalidade, o Paic apoia os municípios na formulação e implementação de políticas voltadas para a garantia do direito de aprendizagem, com prioridade para a alfabetização. É uma política situada no marco do regime de colaboração. Lançado como política pública em 2007, os 184 municípios cearenses aderiram ao Programa, que tem alcançado resultados expressivos na alfabetização de crianças. Para compreensão uma mais clara do regime de colaboração, é preciso que se atente para o fato de que a matrícula no ensino fundamental, no Ceará, foi fortemente municipalizada: em 2009, por exemplo, apenas $16 \%$ das matrículas do segundo segmento do ensino fundamental eram ofertadas pela rede estadual (BRASIL, 2009).

Este artigo apresenta elementos que marcam o que se considera um padrão de cooperação criado pelo Paic. Os sistemas de ensino do estado e dos municípios do Ceará assumiram atribuições, estabeleceram procedimentos, construíram formas de articulação e desenvolveram modos de trabalhar em conjunto. Também é objetivo do artigo compartilhar resultados alcançados pelo Programa e elencar desafios para sua continuidade.

Este trabalho é resultado de um processo de sistematização do Programa, realizado pelas autoras, para elaboração da publicação Regime de colaboração para a garantia do direito à aprendizagem: o Programa Alfabetização na Idade 
Certa (PAIC) no Ceará, coordenada pela Secretaria de Estado da Educação do Ceará (SEDUC) e pelo Unicef. ${ }^{1}$

O processo de sistematização foi conduzido de acordo com a seguinte metodologia: leitura de materiais variados sobre o Paic; realização de entrevistas semiestruturadas com diferentes atores engajados no Programa (gestores da Seduc, parceiros, secretários municipais de Educação, técnicos estaduais e municipais, diretores de escola, coordenadores pedagógicos e professores); discussão de versões preliminares do texto em duas oficinas, uma com um grupo técnico formado por membros da Seduc, representantes dos municípios e parceiros do Paic e outra com um grupo consultivo de especialistas. ${ }^{2} \mathrm{O}$ artigo não é, portanto, resultado de uma avaliação ou de pesquisa acadêmica, mas de uma intenção de sistematização do Programa.

\section{ESPECIFICIDADES DO PADRÃO DE COLABORAÇÃO CRIADO PELO PAIC}

- Reconhecimento do problema do analfabetismo escolar no estado

O Paic tem origem no Comitê Cearense para Eliminação do Analfabetismo Escolar³ que, em 2004, realizou uma avaliação amostral dos níveis de leitura, escrita e compreensão de texto de oito mil alunos da $2^{\underline{a}}$ série do ensino fundamental (atual 3ำ ano), em 48 municípios do estado. Os resultados indicaram que $39 \%$ dos alunos não leram o texto; $15 \%$ leram muito mal, soletrando e sem compreender; $31 \%$ leram com dificuldade e compreenderam parcialmente; e apenas 15\% leram e compreenderam (AGUIAR; GOMES; CAMPOS, 2006). A pesquisa evidenciou o problema do analfabetismo escolar no estado, sendo a base da mobilização de atores diversos e a articulação de uma rede de parceiros para buscar e experimentar soluções.

- Disseminação da ideia de que há uma idade certa para a alfabetização de crianças

O Paic disseminou a ideia de que há uma "idade certa” para a alfabetização de crianças e que esta pode e deve ser medida. Algumas educadores questionaram o termo, alegando que sempre é tempo para aprender: o uso

1 A publicação tem lançamento previsto para o primeiro semestre de 2012 e estará disponível nas páginas da Secretaria de Estado da Educação do Ceará e do Unicef na internet.

2 Informações detalhadas sobre a metodologia de sistematização poderão ser encontradas na publicação.

3 O Comitê foi presidido pela Assembleia Legislativa e teve como parceiros técnicos universidades e instituições da sociedade civil, coordenados pelo Unicef. 
da nomenclatura poderia excluir aqueles que porventura não conseguiram ou não puderam ser alfabetizados na idade especificada. O Programa expressa a compreensão de que o processo de aprender a ler e a escrever começa antes e vai além do $2^{\circ}$ ano. Considera que, sem dúvida, sempre é tempo de aprender, e que todos os que não foram alfabetizados nos anos iniciais devem ter outras oportunidades de aprendizado. Entretanto, o Paic estima que para o bom desenvolvimento escolar da criança é preciso ter metas para que a alfabetização inicial, marcada pelo domínio das habilidades básicas de leitura e escrita, ocorra até os sete anos (cf. a Tabela 1, para os níveis de desempenho esperados).

- Definição de uma bandeira de luta: a alfabetização na idade certa

A prioridade da alfabetização representa uma bandeira de luta. Tem a vantagem de ser algo claro e concreto, constituindo-se em uma aprendizagem mensurável, o que facilita a comunicação tanto para os atores educacionais quanto para a sociedade.

- Desenvolvimento de um piloto

Concluído o trabalho do Comitê Cearense para Eliminação do Analfabetismo Escolar, os atores envolvidos aproveitaram a mobilização social em torno do combate ao analfabetismo escolar e criaram o Programa Alfabetização na Idade Certa. 0 objetivo era apoiar os municípios cearenses na melhoria da qualidade do ensino da leitura e escrita nos anos iniciais do ensino fundamental. Coordenada pela Associação dos Municípios e Prefeitos do Estado do Ceará (APRECE) e União dos Dirigentes Municipais de Educação do Ceará (UNDIME-CE), com parceria técnica e financeira do Unicef, a primeira fase do Paic se estendeu de 2005 a 2006 e envolveu 56 municípios. A principal ação desenvolvida foi a realização de duas avaliações externas em leitura e escrita dos alunos do $2^{\circ}$ ano, de caráter censitário. A avaliação diagnóstica da aprendizagem dos alunos era considerada a primeira etapa para a formulação de estratégias e implantação de ações visando à alfabetização de cada criança da rede de ensino.

- Transformação da alfabetização de crianças em uma prioridade de Estado

O governo do estado assumiu a alfabetização de crianças na idade certa como prioridade e transformou o Programa em uma política pública coordenada pela Secretaria de Estado de Educação (SEDUC). Com essas iniciativas, o estado reconheceu o analfabetismo escolar como um problema de todos e formulou o Paic como um Programa de cooperação com os municípios. 
- Aproveitamento de aprendizagens de experiências prévias

Juntamente com as recomendações elaboradas com base nas pesquisas realizadas pelo Comitê Cearense para Eliminação do Analfabetismo Escolar e do trabalho realizado pela primeira fase do Paic, a estruturação do Programa como política pública se beneficiou da experiência dos gestores da Seduc na implantação de uma política com foco na aprendizagem e prioridade para a alfabetização nos anos iniciais do ensino fundamental no município de Sobral-CE (INEP/MEC, 2005). Os resultados expressivos da política educacional de Sobral deram legitimidade às propostas do Paic: em 2005, o Ideb do município foi de 4,0, em 2007 subiu para 4,9 e em 2009 alcançou 6,6. A melhoria do desempenho dos alunos não ocorreu em detrimento da taxa de aprovação, que era de $94 \%$ em 2005 e chegou a 100\% em 2009.

- Abordagem sistêmica para atuar sobre o problema do analfabetismo escolar

Alfabetizar todos os alunos das redes municipais até o $2^{0}$ ano do ensino fundamental foi o objetivo geral estabelecido para o Paic. Com a crença de que priorizar a alfabetização exige planejar e executar ações sistêmicas e articuladas, o Programa foi organizado em cinco eixos: Gestão da Educação Municipal, Avaliação Externa, Alfabetização, Formação do Leitor e Educação Infantil.

- Foco na aprendizagem da leitura e escrita para iniciar o Programa

A aprendizagem do aluno évista no Paic como um direito fundamental, em torno do qual as atividades realizadas nos municípios e escolas devem convergir. O Programa leva os municípios e escolas a priorizarem a alfabetização de todas as crianças até os sete anos de idade. Privilegiar a alfabetização não significa que outras disciplinas, como a Matemática, principalmente, não sejam reconhecidas como importantes ou até prioritárias nos anos iniciais do ensino fundamental. A Seduc julgou ser estratégico eleger um foco para iniciar o Programa.

- Criação de um arranjo organizacional para viabilizar a cooperação entre estado e municípios

Uma das primeiras providências tomadas pela Seduc no início da gestão foi a criação da Coordenadoria de Cooperação com os Municípios (COPEM), com pessoal e orçamento próprios para viabilizar e fortalecer o regime de colaboração. O Paic está inserido nessa Coordenadoria. Como extensão 
regional da Copem, foram implantados nas 20 Coordenadorias Regionais de Desenvolvimento da Educação (CREDES) ${ }^{4}$ os Núcleos Regionais de Cooperação com os Municípios (NRCOMs).

A criação da Copem e dos NRCOMs foi fundamental para operacionalizar o regime de colaboração, significando um avanço na resolução do arranjo organizacional. Com as coordenadorias, a Seduc pôde cooperar com os municípios sem sobrecarregar as equipes que atuam no apoio à sua própria rede. 0 arranjo pode ser utilizado considerando-se diferentes objetivos e prioridades que venham a ser estabelecidos.

- Constituição das equipes municipais do Paic

O arranjo organizacional do Paic compreendeu ainda a constituição de equipes municipais para atuação no Programa. Lideradas por um gerente, as equipes obedecem a uma divisão similar à assistida na Copem: três ou mais pessoas (a depender do tamanho do município e da estrutura da Secretaria Municipal de Educação) se dividem na execução das ações dos eixos do Programa.

Como forma de estimular a estruturação e organização das equipes municipais do Paic, a Seduc instituiu uma bolsa no valor de $\mathrm{R} \$ 1.000,00$, viabilizada pelo Programa de transferência tecnológica. Os municípios têm liberdade para dividir a bolsa entre os membros das equipes da forma que acharem mais adequada.

Alguns relatos indicam que a bolsa pode causar desagregação das equipes do Paic em relação às demais, quando a intenção é justamente a contrária: integrá-las aos demais setores das Secretarias.

- Responsabilização pelo direito de aprender

Com a criação da Copem e a implementação do Paic, o governo do Ceará empreende um investimento na cooperação com o município, buscando colocar-se como parceiro e corresponsável pela educação municipal. Ao reconhecer os baixos resultados de alfabetização de crianças e o fato de que os municípios têm dificuldades relativas às competências técnicas necessárias para gerir suas redes, o estado oferece um apoio para a consecução de um objetivo comum, contribuindo para que a alfabetização das crianças aconteça. Com o Paic, o governo estadual assume a responsabilidade de Estado pela garantia do direito das crianças à aprendizagem da leitura e da escrita e busca os municípios e escolas a assumirem as suas.

4 A representação da Seduc nas diversas regiões do estado é feita por meio das Credes. 
Nesse processo, procura-se reservar um lugar especial aos chefes de governo e titulares das pastas de Educação. Incentiva-se o desenvolvimento de lideranças que assumam as prioridades da educação e criem, de fato, condições de trabalho para que os objetivos estabelecidos possam ser alcançados.

- Definição das atribuições dos entes federados em arranjos pelo provimento da educação pública

$\mathrm{Na}$ instauração do processo de responsabilização dos entes federados, - Paic contribui com a definição das atribuições e papéis do estado e municípios em arranjos pelo provimento da educação pública, assim como no estabelecimento das formas de articulação entre eles.

A adesão dos prefeitos ao Paic foi formalizada em um Protocolo de Intenções (CEARÁ, 2007a), celebrado juntamente com o governador e a secretária de Educação do Ceará. À Seduc coube prestar assessoria técnica nos eixos do Programa, respeitar o princípio de autonomia dos entes federados e adequar suas ações à realidade e à diversidade dos municípios. Incumbiu-se ainda de avaliar os resultados das capacidades de leitura dos alunos do $2^{\circ}$ ano. Os municípios ficaram responsáveis por fornecer o apoio logístico e os materiais necessários para a realização das atividades do Programa e por disponibilizar as equipes técnicas locais para implementação das propostas.

Com o Paic, o governo do estado coloca-se como parceiro e corresponsável pela educação municipal. A Seduc se firma de fato como uma Secretaria de Educação do Estado do Ceará, e não da rede de ensino estadual cearense. 0 estado tem assumido um papel de fortalecedor das competências de todos os seus municípios, tarefa que nenhum município individualmente teria condição de liderar.

- Disseminação da crença de que é possível alfabetizar as crianças na idade certa

De acordo com a Seduc, o Paic despertou nos gestores e profissionais da educação a crença de que é possível alfabetizar as crianças na idade certa, independentemente de sua condição social.

- Estabelecimento de parcerias com instituições da sociedade civil e organismo multilateral

O Paic mantém um comitê de articulação dotado de funções consultivas e 
fiscalizadoras, previstas em um Termo de Parceria (CEARÁ, 2007b). 0 comitê é formado por: Associação para o Desenvolvimento dos Municípios do Estado do Ceará (APDM-CE), Aprece, Fórum de Educação Infantil, Secretaria de Estado da Cultura do Ceará (Secult), Undime-CE e Unicef. A partir de 2011, a União Nacional dos Conselhos Municipais de Educação (UNCME) passou a integrar o comitê.

- Articulação de parcerias com a universidade e/ou consultorias

A participação de universidades é viabilizada por meio de parcerias ou consultorias de especialistas, que trabalham de acordo com um propósito definido.

- Adoção de mecanismos para estimular a priorização da alfabetização

A priorização da alfabetização na idade certa pelos municípios foi estimulada pela vinculação da distribuição da cota-parte do Imposto sobre Circulação de Mercadorias e Serviços (ICMS) aos municípios a indicadores de educação, saúde e meio ambiente (com o maior peso para os indicadores relativos à alfabetização) (Decreto no 29.306/2008) e pela criação do Prêmio Escola Nota Dez (Lei no 14.371/2009), que concede dinheiro às escolas com os melhores resultados de alfabetização do estado.

O Prêmio Escola Nota Dez é destinado às escolas públicas que obtêm melhor resultado de alfabetização, expresso por meio do Índice de Desempenho Escolar - Alfabetização (IDE-Alfa). São premiadas até 150 escolas que tenham alcançado pontuação entre 8,5 e 10 no índice. ${ }^{5}$ A lei estadual também contempla com recursos financeiros as 150 escolas com os menores IDE-Alfa. Para receber parte de seu prêmio, as escolas premiadas precisam apoiar por um ano uma escola que tenha IDE-Alfa entre os 150 mais baixos do estado, de modo a elevar seu índice. Pretende-se fomentar a cooperação técnicopedagógica entre as escolas.

- Criação de uma dinâmica de apoio técnico aos municípios

Os municípios são apoiados pela Seduc nos cinco eixos do Paic por meio da realização de encontros de formação, reuniões para troca de experiências, acompanhamento in loco e informatizado e disponibilização de instrumentos

5 Uma das metas de gestão do Paic é a nucleação das escolas com um número reduzido de alunos, muitas vezes agrupados em uma única sala multisseriada da educação infantil ao $5^{0}$ ano do ensino fundamental. Para estimular a consecução da meta, foi definido como critério de premiação que as escolas precisam ter no mínimo 20 alunos matriculados no 2o ano. 
e materiais de apoio.

- Apoio ao fortalecimento dos processos de gestão municipal (Eixo Gestão Municipal da Educação)

As ações de gestão são pautadas pelo desenvolvimento de uma cultura de ação cíclica calcada em planejamento (com base na realização de diagnóstico e definição de metas), intervenção, acompanhamento, monitoramento e avaliação, que apoie a estruturação e a implantação de uma política municipal. Para isso, a Seduc disponibiliza instrumentos às secretarias municipais de Educação, desenvolve ações de formação dos quadros municipais e apoia tecnicamente as equipes na definição de metas, elaboração de planos e acompanhamento e avaliação de processos e indicadores.

Por meio de formações e promoção de encontros para troca de experiências, a Seduc também coopera tecnicamente com os municípios para adotarem os seguintes processos: nucleação das escolas; cumprimento do calendário legal de 200 dias letivos e 800 horas-aula; fortalecimento da autonomia das escolas; elaboração de política de acompanhamento das escolas da rede municipal; definição de critérios técnicos para o processo de seleção de gestores escolares, com priorização do mérito; revisão dos planos de cargos, carreira e remuneração do magistério municipal; estabelecimento de política de formação de professores e definição de critérios focados no mérito para a contratação de professores.

Apesar de serem processos que têm incidência direta na promoção da alfabetização de crianças, geram um impacto que se estende a toda Secretaria de Educação. É disseminado um modelo de gestão.

- Disseminação da prática de avaliação externa para a intervenção pedagógica

O Paic investe no desenvolvimento da capacidade de os municípios planejarem e executarem avaliações externas às escolas e forma as equipes municipais e escolares para utilizar os resultados das provas como instrumentos para a intervenção pedagógica. Para tanto, desenvolve junto aos municípios a Provinha Paic, instituída com o objetivo de proporcionar um diagnóstico da alfabetização dos alunos dos anos iniciais do ensino fundamental para subsidiar o planejamento das intervenções pedagógicas pelos municípios e escolas. 0 teste (composto por itens de múltipla escolha e itens abertos) é construído a partir de uma matriz de referência dividida em três eixos: apropriação do sistema de escrita, leitura e escrita. 
De caráter censitário, a Provinha Paic é aplicada sempre no início do primeiro semestre letivo, a fim de propiciar tempo para que ocorram as intervenções pedagógicas planejadas para sanar as dificuldades. Dado seu caráter diagnóstico, os resultados dos municípios não são utilizados para composição de classificações nem são divulgados publicamente. Os municípios recebem apenas seus próprios dados (em relatórios por município, escola, turma e aluno) e o consolidado geral do estado.

A Seduc, com apoio da Universidade Federal do Ceará, disponibiliza as provas e forma as equipes municipais para aplicá-las e corrigi-las.

A Seduc também avalia os alunos do $2^{\circ}$ ano do ensino fundamental por meio do Sistema Permanente de Avaliação da Educação Básica do Estado do Ceará - Alfabetização (Spaece Alfa), desenvolvido via Coordenadoria de Avaliação e Acompanhamento da Educação. No Spaece Alfa, o município não é envolvido na aplicação da avaliação dos testes, uma vez que esta é uma responsabilidade do Centro de Políticas Públicas e Avaliação da Educação (CAED) da Universidade Federal de Juiz de Fora (UFJF). As provas são realizadas ao final do ano letivo, a fim de servir de parâmetro de avaliação dos esforços do estado e dos municípios na alfabetização das crianças. Diretores e professores respondem a questionários contextuais que abordam dados socioeconômicos e práticas pedagógicas e de gestão. É por meio do Spaece Alfa que o governo do estado elabora o mapa da alfabetização e calcula os índices que balizam a distribuição da cota-parte do ICMS e o Prêmio Escola Nota Dez. Diferentemente da Provinha Paic, o Spaece Alfa avalia somente leitura e tem seus resultados expressos em níveis de proficiência, utilizando para isso a Teoria de Resposta ao Item e a escala de desempenho da Provinha Brasil, do MEC.

A Seduc produz e divulga publicamente uma classificação geral dos resultados dos municípios e escolas no Spaece Alfa. Os resultados são amplamente noticiados na imprensa. Os gestores estaduais defendem que a divulgação funciona como uma prestação de contas para a sociedade e possibilita o acompanhamento dos indicadores educacionais do estado. Creem que contribui para o engajamento do prefeito, do secretário municipal de Educação e do diretor de escola no Programa, uma vez que os resultados têm visibilidade em todo o Ceará.

O Paic procura fazer com que os resultados da avaliação externa (tanto da Provinha Paic quanto do Spaece Alfa) sejam de fato utilizados pelas equipes municipais e escolares como instrumentos de intervenção pedagógica. 
Acredita-se que a apropriação dos resultados, o aperfeiçoamento da prática pedagógica e a adequação de elementos de gestão é que irão provocar as mudanças esperadas na aprendizagem dos alunos.

Para isso, a Seduc conduz uma ação formativa sistemática, baseada em encontros de capacitação, oficinas para apresentação e análise dos dados, acompanhamento técnico e disponibilização de instrumentos, tudo com o foco no desenvolvimento da capacidade de compreensão e interpretação dos resultados e formulação de estratégias de intervenção pedagógica. Essas ações envolvem desde o secretário municipal até o professor alfabetizador.

Nas análises, as equipes municipais e escolares são capacitadas para entender e interpretar os dados das avaliações, construindo hipóteses explicativas para os aspectos que interferiram positiva e negativamente nos resultados. São orientados a irem além das médias gerais: a ideia é que não basta melhorar o nível médio do município e das escolas, e sim obter avanços na proficiência de todos os alunos, principalmente daqueles com resultados nos níveis mais críticos.

Professores são orientados a enriquecer a análise com a avaliação do processo de aprendizagem realizada no contexto da sala de aula por meio de observações, relatórios, diários de bordo e portfólios, entre outros instrumentos. 0 objetivo é que o docente reúna mais elementos para planejar as intervenções pedagógicas necessárias.

- Articulação da formação de professores ao currículo e ao uso de material estruturado (Eixo Alfabetização)

Com a intenção de retomar o uso de metodologias de alfabetização de crianças em sala de aula, a Seduc coopera com os municípios no desenvolvimento de um Programa de formação de professores articulado ao currículo, à distribuição de material estruturado (conjunto de materiais diversificados destinados a professores e alunos que, com base em metodologias de alfabetização, propõem uma rotina diária de atividades para a sala de aula e tarefas de casa) e ao acompanhamento pedagógico.

Duas estratégias distintas foram desenvolvidas para a elaboração dos materiais e a formação de professores. Para $01^{\underline{0}}$ ano do ensino fundamental, a opção foi criar um material único; para o $2^{\circ}$ ano, o estado disponibiliza para escolha dos municípios um leque de materiais elaborados por editoras e selecionados pela Seduc a partir de um edital. A formação de professores é articulada ao material, sendo ministrada pela Seduc no primeiro caso e por 
especialistas contratados pelas editoras, no segundo.

No Paic, os materiais estruturados são oferecidos como uma base para 0 professor, que é estimulado a exercer sua criatividade na preparação das aulas a partir do que é proposto. Os livros do Programa Nacional do Livro Didático (PNLD) continuam sendo distribuídos às escolas cearenses, que são orientadas pela Seduc a usá-los de forma complementar.

- Valorização do professor por meio da melhoria da sua capacidade de alfabetização

De acordo com os depoimentos dos gestores da Seduc, o Paic está criando um ambiente de valorização do professor, com o desenvolvimento do programa de formação voltado para a alfabetização, disponibilização de material didático estruturado e apoio pedagógico. A edição da revista Pense! e da agenda do Paic, a criação dos Clubes de Leitura e outras ações também voltadas para os docentes, como a participação na Bienal do Livro, fomentam o gosto pela leitura junto aos profissionais da educação e reforçam a capacidade alfabetizadora do professor.

O uso da avaliação externa como instrumento de gestão e de intervenção pedagógica, articulado à definição de metas e ao acompanhamento educacional, deu grande visibilidade aos resultados das provas em larga escala. Com a adoção da prioridade na alfabetização na idade certa, os holofotes se centraram nos resultados das gestões municipais, escolas e, por consequência, professores e suas turmas, o que deixou inicialmente alguns professores insatisfeitos. A melhoria do desempenho dos alunos passou a ser uma meta pela qual as escolas precisam zelar.

Gestores municipais e membros de equipes escolares relatam que houve alguns casos de docentes que optaram por deixar as turmas de alfabetização. $A$ maior parte dos professores, no entanto, segundo os entrevistados e gestores do Paic, aderiu ao Programa e demonstrou grande comprometimento com o objetivo de alfabetizar todos os seus alunos até os sete anos. Contribuiu para isso o reconhecimento de que a responsabilização pela aprendizagem dos alunos não recai somente neles, e sim em toda a rede envolvida na educação municipal, que age em sinergia para a realização de um bom trabalho junto aos alunos. Com isso, desvincula-se a importância dada aos resultados de aprendizagem da ideia de cobrança vinculada à culpabilização.

Na visão da Seduc, a formação e o apoio pedagógico recebidos pelo professor, juntamente com a melhoria gradativa dos resultados das avaliações externas, 
estão fortalecendo a autoestima docente e fazendo com que se vejam como profissionais valorizados e capazes de alfabetizar. Sentem-se reconhecidos em ver, nos resultados de desempenho dos alunos, o retorno do seu esforço.

- Desenvolvimento de ações voltadas à formação de leitores (Eixo Formação do Leitor)

O objetivo do Paic de formar leitores e fomentar o gosto pela leitura está pautado no pressuposto de que a alfabetização e o letramento devem ser promovidos de forma integrada e indissociável. Para o Programa, a aprendizagem da leitura representa a aquisição de uma nova linguagem, que permite 0 acesso a conhecimentos e informações, ampliação de horizontes, desenvolvimento de capacidade crítica e exercício da cidadania.

A principal estratégia do Eixo de Formação do Leitor é a criação e dinamização de acervos literários nas salas de aula por meio da implementação de cantinhos de leitura em todas as salas de aula de educação infantil e $1^{\underline{0}}$ e $2^{\circ} \underline{0}$ anos do ensino fundamental.

A criação dos acervos de literatura infantil é conduzida por dois processos: aquisição de títulos publicados por editoras e edição de livros próprios, por meio de um edital lançado para escritores residentes no estado.

Professores foram formados em oficinas de dinamização dos acervos de literatura infantil, com oficinas de contação de histórias, leitura de imagem e utilização de gêneros textuais diversos, teatro de bonecos, musicalização de histórias e criação literária.

O desafio de fomentar o gosto pela leitura não é apenas junto às crianças. A Seduc implementou estratégias junto ao magistério, com o objetivo de fortalecer o hábito de ler: como se indicou anteriormente, é editada uma revista do Paic (Pense!), uma agenda e foram implantados Clubes de Leitura nos municípios.

- Fortalecimento da educação infantil (Eixo Educação Infantil)

Reconhece-se a educação infantil como uma etapa da Educação Básica indispensável na preparação para a alfabetização que será consolidada nos anos iniciais do ensino fundamental. A Seduc apoia os municípios no estabelecimento de políticas para as crianças pequenas, incluindo a elaboração de propostas pedagógicas e a formação dos professores, e 
colabora com a construção de Centros de Educação Infantil nos municípios.

- Fomento ao intercâmbio de experiências entre os municípios

O estado buscou constituir uma rede de aprendizagem a partir do incentivo ao estabelecimento de relações entre os municípios engajados no Programa. Prefeitos, secretários de Educação, gerentes municipais do Paic e outros profissionais participam de eventos de intercâmbio de experiências, realizados em reuniões promovidas pelas Credes e em seminários realizados pela Copem. Ainda que seja uma rede sustentada diretamente pela Seduc, a interação entre os municípios tem ocorrido e avalia-se que tenha potencial de se intensificar. O Prêmio Escola Nota Dez, na medida em que prevê o intercâmbio entre escolas com bons resultados de alfabetização de crianças e aquelas com baixos indicadores, também viabiliza esse tipo de colaboração.

- Apoio diferenciado aos municípios considerados prioritários

Municípios considerados prioritários devido aos seus baixos resultados nas avaliações padronizadas têm intensificado o apoio da Seduc. A equipe da Copem se soma ao trabalho das Credes, indo aos municípios realizar o acompanhamento in loco. Os gestores e técnicos da Copem se reúnem com o prefeito, o secretário de Educação e a equipe municipal do Paic, vão às escolas, assistem às aulas, conversam com as crianças, professores, coordenadores e diretores.

O acompanhamento é guiado por um roteiro que orienta a elaboração de relatórios que, sistematizados, apontam questões comuns aos municípios considerados prioritários. A sistematização subsidia o apoio da Seduc aos municípios, pautando formações e encontros.

- Ausência de diferenciação política dos municípios na consecução do apoio pelo governo do estado

Na cooperação com os municípios, o estado tem o cuidado político de não tratar de maneira diferenciada prefeitos da base aliada ou de opositores do governo. 0 apoio é dado a todos da mesma maneira; distinções ocorrem apenas nos casos de municípios considerados prioritários devido aos seus resultados, que demandam auxílio diferenciado dos demais. Fortalece-se, assim, a noção de que o aspecto técnico da educação deve ser valorizado em detrimento de critérios políticos, entendimento defendido também nos municípios, que são orientados a "protegerem” a educação das interferências político-partidárias. 


\subsection{Resultados}

O Programa é recente e muitos desafios se impõem, ainda que já se verifique uma evolução nos indicadores de alfabetização de crianças no estado. Em 2007, primeiro ano do Paic como política pública, a Secretaria de Educação realizou uma avaliação da capacidade de leitura dos alunos da rede pública do $2^{\circ}$ ano do ensino fundamental por meio do Spaece Alfa. De caráter universal, a prova proporcionou uma linha de base para avaliação do Programa ao longo dos anos. Os dados (exibidos na Figura 1) mostram que a média de desempenho estadual em leitura cresceu de $118,9,{ }^{6}$ em 2007, a 162,6, em 2010 , indicando um aumento de 43,7 pontos.

FIGURA 1 - Evolução das médias de desempenho municipais

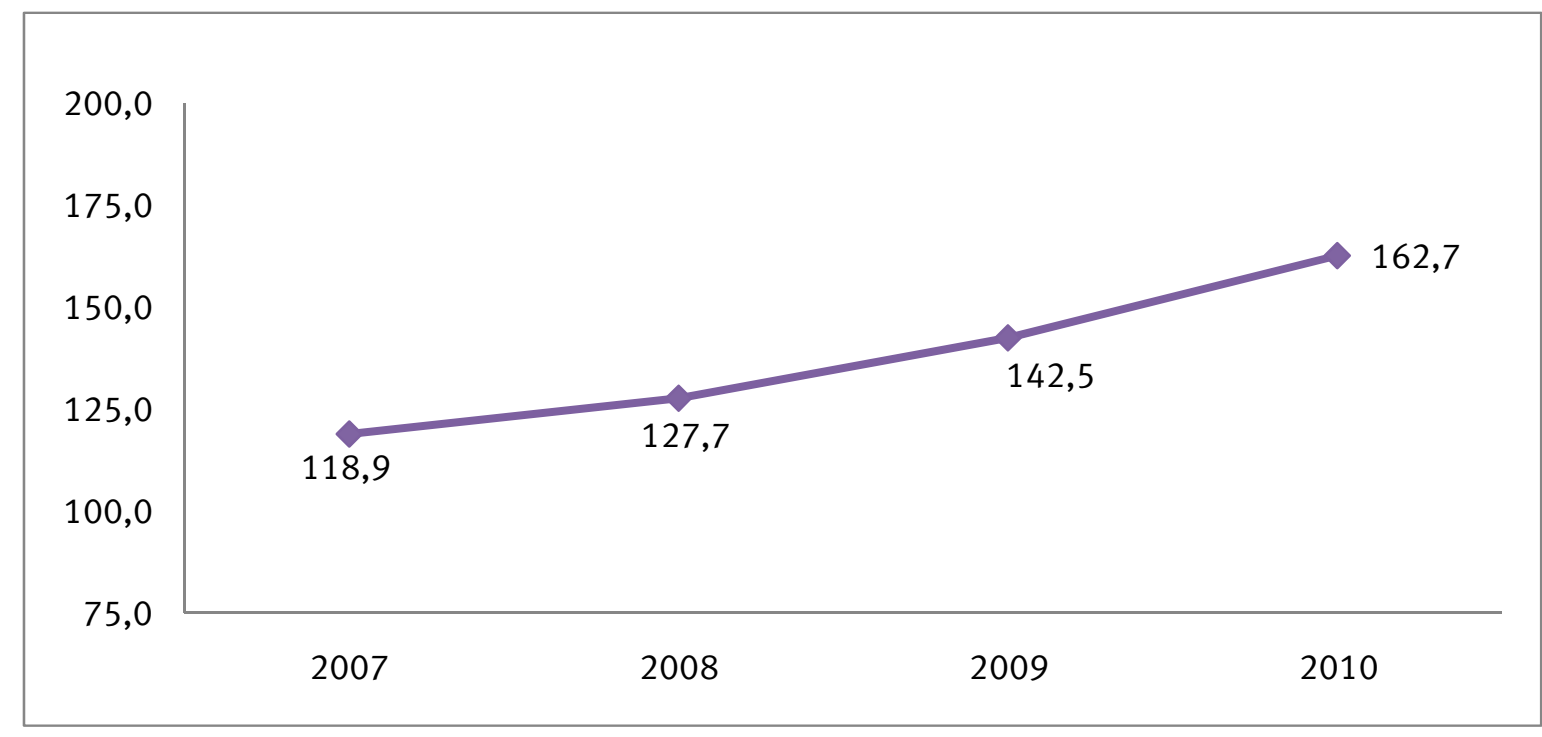

Fonte: Spaece Alfa/Seduc-CE.

A escala utilizada para medir o nível de competência das crianças tem cinco níveis de alfabetização. Para facilitar a visualização dos níveis, cada um deles é expresso por uma cor distinta: não alfabetizado (branca), alfabetização incompleta (vermelha), intermediário (laranja), suficiente (verde-claro) e desejável (verde-escuro).

6 A matriz de referência utilizada foi elaborada coletivamente por técnicos, professores e especialistas da Seduc-CE, do Centro de Políticas Públicas e Avaliação da Educação da Universidade Federal de Juiz de Fora (CAEd/UFJF) e da Universidade Federal do Ceará, em sintonia com a matriz e a escala da Provinha Brasil, do Inep. 
TABELA 1 - Escala de interpretação pedagógica do Spaece Alfa

\begin{tabular}{|c|c|c|c|c|c|}
\hline & \multirow{2}{*}{\multicolumn{5}{|c|}{ Padrão de desempenho }} \\
\hline & & & & & \\
\hline & Não alfabetizado & $\begin{array}{l}\text { Alfabetização } \\
\text { incompleta }\end{array}$ & Intermediário & Suficiente & Desejável \\
\hline $\begin{array}{l}\text { Nível de } \\
\text { proficiência }\end{array}$ & 0 a 75 pontos & 75 a 100 pontos & $\begin{array}{l}100 \text { a } 125 \text { pon- } \\
\text { tos }\end{array}$ & $\begin{array}{l}125 \text { a } 150 \text { pon- } \\
\text { tos }\end{array}$ & $\begin{array}{l}\text { Acima de } 150 \\
\text { pontos }\end{array}$ \\
\hline $\begin{array}{l}\text { Interpretação } \\
\text { (resumo) }\end{array}$ & $\begin{array}{l}\text { Indica que o } \\
\text { aluno ainda não } \\
\text { se apropriou do } \\
\text { sistema de es- } \\
\text { crita, não tendo } \\
\text { desenvolvido ha- } \\
\text { bilidades básicas } \\
\text { para o aprendiza- } \\
\text { do da leitura e da } \\
\text { escrita. }\end{array}$ & $\begin{array}{l}\text { Início do proces- } \\
\text { so de domínio e } \\
\text { sistematização } \\
\text { de habilidades } \\
\text { consideradas } \\
\text { básicas e essen- } \\
\text { ciais à alfabeti- } \\
\text { zação. }\end{array}$ & $\begin{array}{l}\text { Indica que o } \\
\text { aluno consegue } \\
\text { ler com auto- } \\
\text { nomia palavras } \\
\text { formadas por } \\
\text { padrões silábicos } \\
\text { diversos e que } \\
\text { começa a com- } \\
\text { preender frases } \\
\text { simples. }\end{array}$ & $\begin{array}{l}\text { Consegue locali- } \\
\text { zar informações } \\
\text { em textos com } \\
\text { cerca de } 50 \text { pala- } \\
\text { vras, identificar o } \\
\text { assunto de uma } \\
\text { narrativa curta } \\
\text { e a finalidade } \\
\text { de um texto de } \\
\text { gênero familiar. }\end{array}$ & $\begin{array}{l}\text { Início do desen- } \\
\text { volvimento de } \\
\text { habilidades pró- } \\
\text { prias de um leitor } \\
\text { proficiente. }\end{array}$ \\
\hline $\begin{array}{l}\text { Cor de } \\
\text { representação }\end{array}$ & Branca & Vermelha & Laranja & Verde-claro & Verde-escuro \\
\hline
\end{tabular}

Fonte: Seduc-CE.

Na Figura 2, o mapa do Ceará com os municípios coloridos de acordo com seu nível médio de proficiência expõe a evolução da alfabetização no estado de 2007 a 2010.

FIGURA 2 - Mapa do Ceará por nível de proficiência dos municípios cearenses no Spaece Alfa - 2007 a 2010.

2007

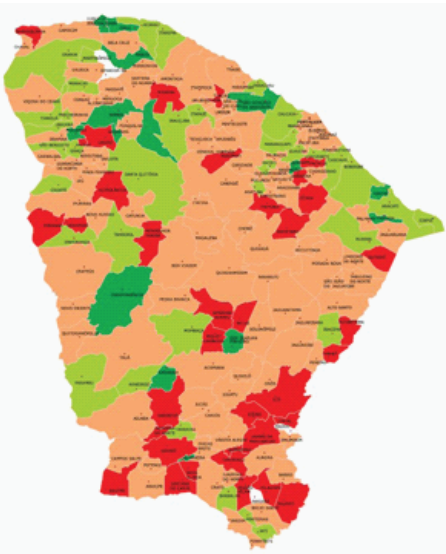

2008

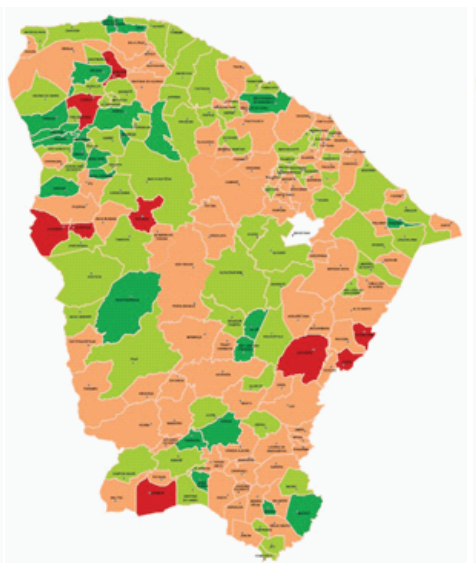

2009

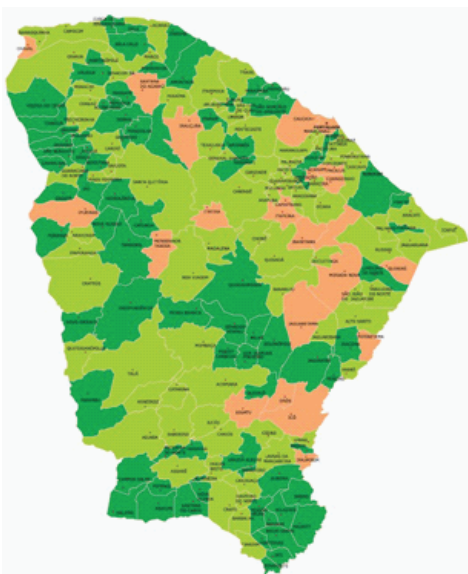

2010

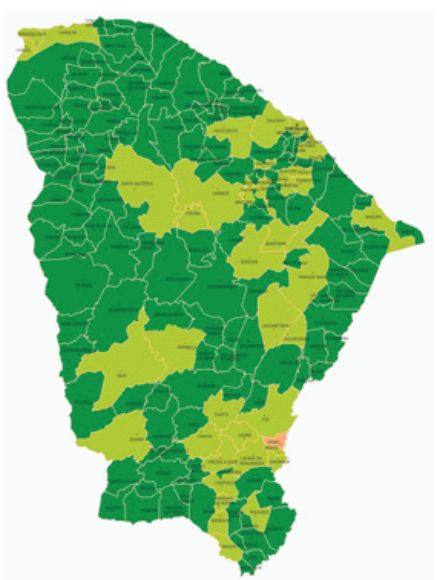

Fonte: Spaece Alfa/Seduc-CE.

A melhoria das médias de proficiência municipais tem sido expressiva. Como é possível observar na Figura 2, em 2007, apenas 26,6\% dos municípios estavam nos dois primeiros níveis (suficiente e desejável); em 2010, o total nesses dois níveis passou para 99,4\%. Dos 184 municípios cearenses, 141 se destacam por apresentarem média de proficiência no nível desejável, sendo que três possuem médias superiores a 250 pontos. 
FIGURA 3 - Distribuição percentual dos municípios por nível de proficiência - 2007 a 2010

\section{Distribuição dos municípios por nível de proficiência (\%)}

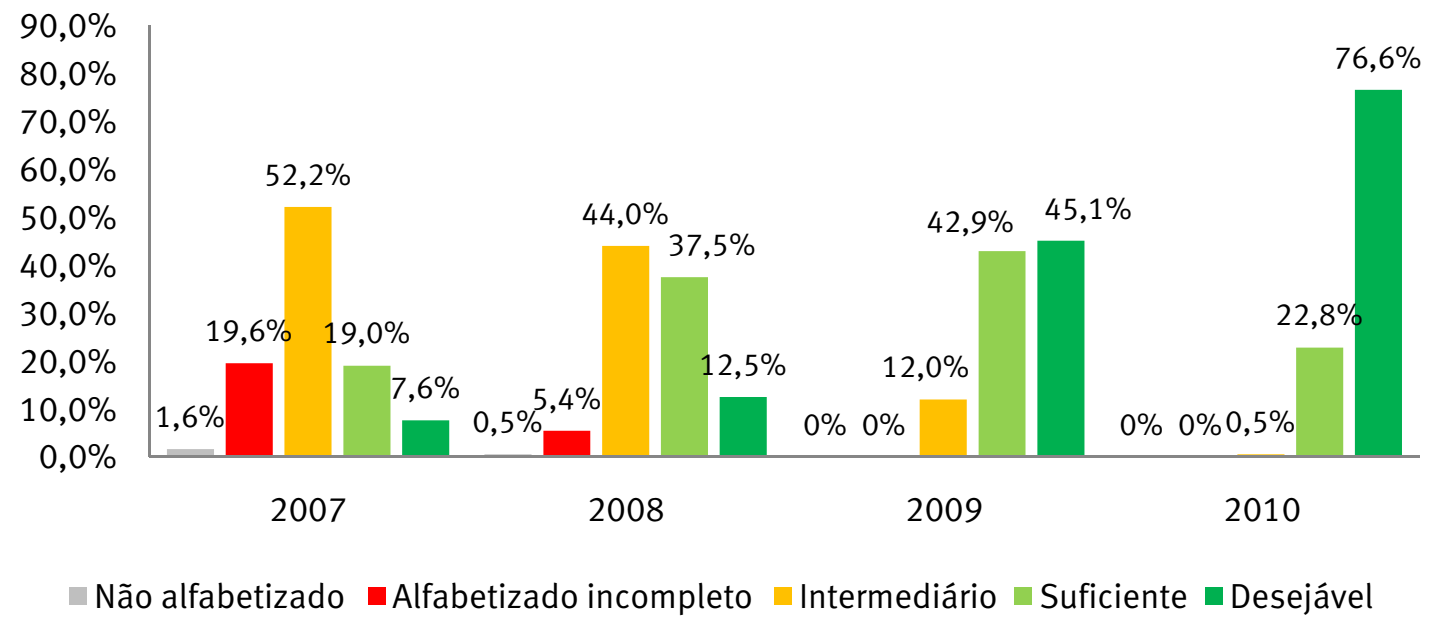

Fonte: Spaece Alfa/Seduc-CE.

Como ilustra a Figura 4, a porcentagem de alunos com proficiência nos níveis mais altos tem aumentado: em 2007, apenas 40\% encontravam-se nos dois primeiros níveis; em 2010, já eram 71\%. 0 total de crianças não alfabetizadas, que era de 33\% em 2007, caiu para 7\% em 2010.

FIGURA 4 - Distribuição percentual dos alunos por nível de proficiência - 2007 a 2010 Distribuição dos alunos por nível de proficiência (\%)

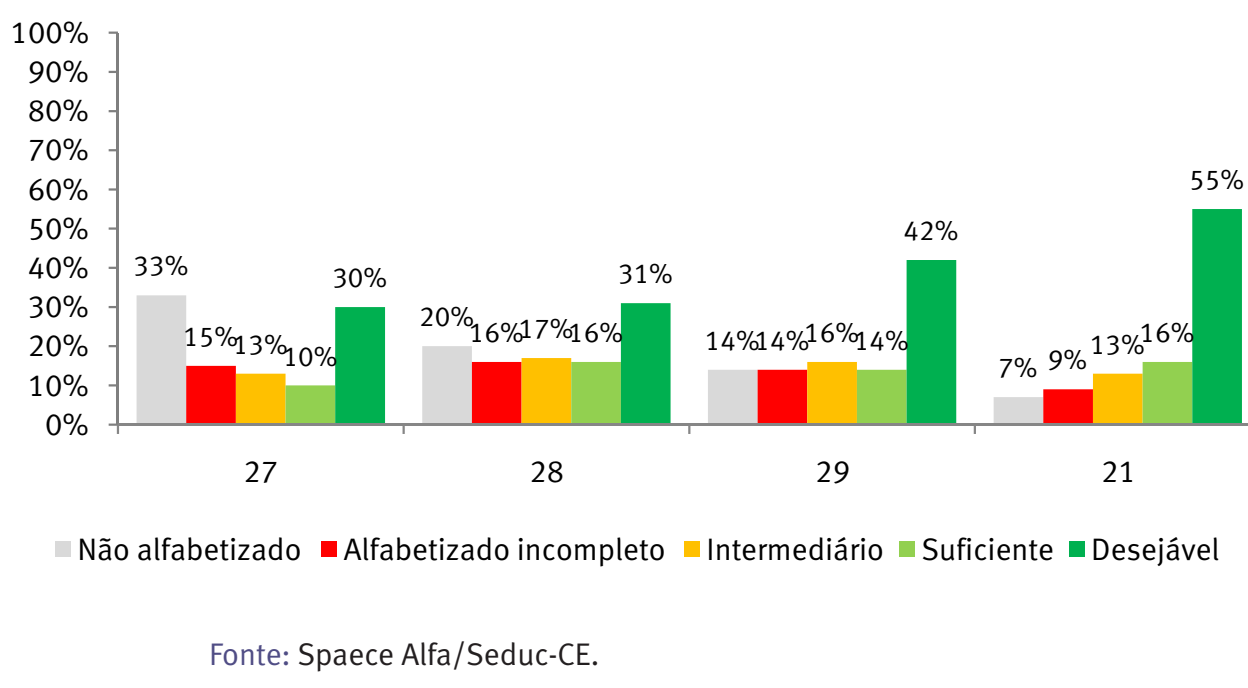

Alguns fatores contextuais podem ter contribuído com a implantação do Paic e o alcance de bons resultados pelo Programa: a tendência de melhoria dos indicadores educacionais no estado desde 2005; a existência de um legado de colaboração educacional e alguns elementos da política educacional e da economia nacional. 
Apesar de ser um estado pobre quando se considera o rendimento mensal per capita, o Ceará tem se destacado positivamente no contexto educacional do Nordeste (região que tradicionalmente apresenta os indicadores educacionais mais baixos do Brasil), expondo números próximos às médias do país. 0 estado tem melhorado seus indicadores gradativamente desde 2005 (período considerado na análise de dados realizada na sistematização). Ainda que as médias Brasileiras também tenham tendência de melhoria, muitas vezes 0 Ceará apresentou um movimento mais intenso.

O Ceará tem um legado de colaboração educacional (OLIVEIRA, S. L., 2010), o que contribuiu para o Paic se firmar como uma política de cooperação. No estado, políticas inseridas no regime de colaboração entre os entes federados são desenvolvidas desde os anos 1970.

A promulgação do Plano de Desenvolvimento da Educação (PDE), especialmente no tocante à disseminação do Ideb como um indicador de qualidade da educação e um cenário econômico propício, de crescimento aliado a uma diminuição da desigualdade social também são elementos a serem considerados.

Cabe observar, entretanto, que embora os fatores relacionados favoreçam a implementação do Programa, esses não são fatores exclusivos para explicar seus bons resultados. Em contextos socioeconômicos e condições similares, localidades alcançam resultados abaixo ou acima do esperado (BROOKE; SOARES, 2008; DUBET; DURU-BELLAT; VÉRÉTOUT, 2010).

\section{DESAFIOS PARA A CONTINUIDADE DO PAIC}

Em 2010, o Paic completou quatro anos. Sua continuidade na gestão 20112014 enseja alguns desafios que repercutem na sustentabilidade do Programa nos municípios. A seguir, são comentados desafios vislumbrados pela Seduc, membros do comitê de articulação do Paic e gestores e técnicos municipais.

\section{a. Qualidade}

Para o Paic, uma educação de qualidade precisa proporcionar o direito de aprender às crianças e aos adolescentes. Dado o quadro do analfabetismo escolar no Ceará, o Programa elegeu a alfabetização na idade certa como primeira prioridade para a cooperação entre estado e municípios. Com a melhoria dos resultados de alfabetização medidos pelos testes em larga escala, emerge o desafio de prosseguir com o apoio aos municípios para 
que fortaleçam sua capacidade de gestão em outras disciplinas importantes, como a Matemática.

Os municípios têm trazido a expectativa de ampliação do Programa para os 3ํㅡㄴ 4ํㅜ e $5^{\circ}$ anos. Eles reconhecem os progressos proporcionados na alfabetização

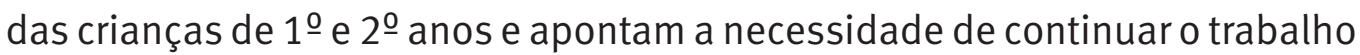
desenvolvido. Em resposta à demanda, a Seduc está estruturando o Paic+, que estenderá as ações do Programa até o $5^{0}$ ano. A extensão do foco para a Matemática, considerada uma disciplina prioritária nos anos iniciais, é outra demanda dos municípios e escolas e está contemplada.

Para os gestores da Seduc, a garantia do direito à aprendizagem envolve a definição dos currículos do estado e a demarcação dos conteúdos que devem ser trabalhados ano a ano de escolaridade. Nesse sentido, a Secretaria Estadual se prepara para avançar na definição curricular.

Pensar em desafios concernentes à promoção da qualidade da educação implica refletir sobre questões derivadas das avaliações externas. Uma delas é o enfoque excessivo no desempenho dos alunos, que, na visão de alguns municípios, tem sido um efeito adverso das novas regras de repartição do ICMS e do Prêmio Escola Nota Dez. Eles relatam que o foco das escolas no desempenho pode levar a exageros, como o treinamento exaustivo dos alunos por meio de testes que simulam a avaliação externa ou relegar a um segundo plano outros pontos relevantes do currículo. Perspectiva que corrobora visões de especialistas que consideram que as avaliações em larga escala são importantes instrumentos de gestão, mas não deveriam se vincular a mecanismos que reduzem o conceito de qualidade da educação à dimensão do desempenho dos alunos e que levam à competição nas escolas (OLIVEIRA, R. P., 2010).

Outra questão que se coloca é a aplicação de mais de um tipo de avaliação externa junto às crianças. Embora tenham finalidades distintas, os alunos de $2^{0}$ ano das redes públicas cearenses participam do Spaece Alfa, da Provinha Paic e, em alguns casos, da avaliação externa municipal. Como se trata de crianças pequenas, de 7 anos de idade, é recomendável a realização de um alinhamento entre estado e municípios com o objetivo de discutir as funções das avaliações externas e o papel de cada uma delas no âmbito da sua realização e utilização.

Faz-se também necessário aperfeiçoar as formas de acompanhamento das metas do Paic por parte dos municípios, inclusive daquelas que dizem mais 
respeito a princípios de gestão.

\section{b. Equidade}

A equidade é um tema que tem emergido com força nos debates na área de educação. A promoção da qualidade para todos implica olhar com cuidado para as diversas desigualdades reveladas pelos indicadores sociais e educacionais. Estudo realizado pelo Unicef mostra que há grupos populacionais em situação mais vulnerável quando se trata do pleno exercício do direito de aprender: crianças mais pobres, negros e pardos, indígenas, quilombolas e crianças e adolescentes com deficiências. Estão também em circunstância de maior fragilidade os moradores de zonas rurais e de comunidades populares de grandes centros urbanos (UNICEF, 2009). Para potencializar seus avanços e promover a alfabetização de todas as crianças até os 7 anos de idade, o Paic precisaria identificar os grupos com maior vulnerabilidade e apoiar os municípios para implantar políticas que levem em conta as desigualdades verificadas.

O objetivo de alfabetização de todas as crianças exige estratégias voltadas para os alunos com mais dificuldades de aprendizagem. Na ampliação do Paic para o restante dos anos iniciais do ensino fundamental, atenção especial merece ser dada às crianças que não foram alfabetizadas até o 20 ano. A alfabetização dos alunos não alfabetizados do 3ํa a 9ํano é uma das metas do Paic, que, até 2010, não tinha se traduzido em ações efetivas.

Visando atuar sobre esse público, em 2011, a Seduc, em parceria com o governo federal, desenvolveu um SOFTWARE para alfabetização denominado Luz do Saber, que pode ser usado por crianças, jovens e adultos.

É preciso adotar outras estratégias que propiciem a consolidação da alfabetização dos alunos matriculados a partir do $3^{\circ}$ ano e que não desenvolveram as habilidades de leitura e escrita esperadas.

\section{c. Participação e controle social}

A participação na elaboração e gestão das políticas educacionais é um desafio da corresponsabilidade pela educação, princípio consagrado pela Constituição de 1988, que determina a educação como direito de todos e dever do Estado e da família, com o qual deve colaborar a sociedade (GHANEM, 2003). Além de ser um direito, a participação dos pais e da comunidade costuma ser avaliada como geradora de potencial de melhorar a qualidade da educação e contribuir para o controle social das políticas. É um desafio 
para o Paic ampliar as formas de participação na definição e implantação de políticas municipais com foco na aprendizagem.

O assunto faz parte da agenda do Programa, que se prepara para, no Paic+, definir orientações para que as escolas estimulem os familiares a estarem mais presentes no processo de educação escolar das crianças.

\section{O PAIC+}

O Paic+ é a ampliação do Programa Alfabetização na Idade Certa. Lançado em maio de 2011, tem o objetivo de elevar os resultados de aprendizagem dos alunos da rede pública até o 50 ano. Resultados do Spaece mostram que, em 2009 , somente $10 \%$ dos alunos estavam no nível adequado em Português e 6,9\% em Matemática. Os municípios estão sendo convidados a aderirem ao Paic+ e assinar uma nova agenda de compromissos proposta pelo governo do estado:

- Continuar cumprindo os compromissos com a alfabetização de crianças no Paic elencados no compromisso anterior.

- Definir políticas de valorização do professor do ensino fundamental I.

- Garantir o transporte, as diárias e a disponibilidade de tempo para os professores multiplicadores participarem das formações e realizá-las no município.

- Oferecer logística para todos os encontros formativos no município.

- Propiciar tempo para os professores do ensino fundamental I participarem das formações, sem comprometer o ano letivo.

- Reproduzir todo o material didático necessário para apoiar professores e alunos no processo formativo.

Os gestores do Paic se pautam por uma visão de mundo que acredita na mudança. Têm feito suas escolhas, pois no mundo da política é fundamental decidir, fazer apostas, executá-las. Têm também corrigido rumos, aperfeiçoado caminhos. Seu percurso e resultados são um convite à reflexão, ao estudo, à comparação de perspectivas. A crítica poderá aprimorá-lo, contribuindo assim para um ciclo que pode ser virtuoso entre a implementação de políticas e a pesquisa rumo ao fortalecimento de políticas educacionais que estão 
surgindo no Brasil diante do desafio da melhoria da qualidade na educação. 


\section{Collaboration between the state and municipalities to make children in Ceará literate at the right age}

\section{ABSTRACT}

This paper is aimed at introducing the Programa Alfabetização na Idade Certa [Literacy at the Right Age Program] (Paic), developed in cooperation between the state and municipal governments of Ceará with the support of Unicef. The Program's main objective is to teach every student in the public school system seven and under to read. By way of an introduction, the paper attempts to describe its chief processes, share its findings, enumerate on the challenges to its longevity, and, specially, highlight what is found to be a standard of state/municipal cooperation aimed at improving the quality of education.

KEYWORDS:

Cooperation; Educational policy; Literacy. 


\section{Referências}

ABICALIL, Carlos; CARDOSO NETO, Odorico Ferreira. Federalismo cooperativo e educação brasileira: a experiência de Mato Grosso [com a] proposição de um sistema único de educação. In: OLIVEIRA, Romualdo Portela; SANTANA, Wagner (Org.). Educação e federalismo no Brasil: combater as desigualdades, garantir a diversidade. Brasília: Unesco, 2010. p. 215-242.

AGUIAR, Rui; GOMES, Ivo; CAMPOS, Márcia. (Org.). Educação de qualidade começando pelo começo: relatório final do Comitê Cearense para a Eliminação do Analfabetismo Escolar. Fortaleza: Assembleia Legislativa do Ceará, 2006. $206 \mathrm{p}$.

ARAÚJO, Gilda Cardoso. Constituição, federação e propostas para o novo Plano Nacional de Educação: análise das propostas de organização nacional da educação brasileira a partir do regime de colaboração. Educação \& Sociedade, Campinas, v. 31, n. 112, p. 749-768, jul./set. 2010.

BRASIL. Censo Escolar 2009. Brasília: MEC/INEP, 2009. Disponível em: http:// www.inep.gov.br/basica/censo/default.asp. Acesso em: 20 set. 2011

BRASIL. Ministério da Educação. Instituto Nacional de Estudos e Pesquisas Educacionais Anísio Teixeira. Vencendo o desafio da aprendizagem nas séries iniciais: a experiência de Sobral/CE. Brasília: INEP, 2005. 171 p. (Série Projeto Boas Práticas na Educação, n. 1.).

BRASIL. Ministério da Educação. PDE/Plano de Desenvolvimento da Educação. Saeb: ensino médio: matrizes de referência, tópicos e descritores. Brasília: MEC; SEB; INEP, 2008.

BROOKE, Nigel; SOARES, José Francisco (Org.). Pesquisa em eficácia escolar: origem e trajetórias. Belo Horizonte: UFMG, 2008.

CEARÁ. Secretaria de Estado da Educação. Protocolo de intenções. Fortaleza: 2007a. 13 p. Disponível em: 〈http://www.idadecerta.seduc.ce.gov.br/pdf/ intencoes.pdf〉. Acesso em: 20 set. 2011.

CEARÁ. Termo de parceria. Fortaleza: 2007b. 7 p. Disponível em: 〈http:// www.idadecerta.seduc.ce.gov.br/pdf/termo_parceria.pdf $\rangle$. Acesso em: 20 set. 2011

CEARÁ. Regime de colaboração para a garantia do direito à aprendizagem: o Programa Alfabetização na Idade Certa (PAIC) no Ceará. Fortaleza: Secretaria de Estado da Educação do Ceará (SEDUC); Unicef. Não publicado. 
DUBET, François; DURU-BELLAT, Marie; VÉRÉTOUT, Antoine. Les sociétés et leur écoles: emprise du diplôme et cohésion sociale. Paris: Seuil, 2010.

GHANEM, Elie. O que pode significar a gestão da educação. Videtur, São Paulo, n. 20, 2003. Disponível em: 〈http://www.hottopos.com/videtur20/ elie.htm>. Acesso em: 03 jun. 2011.

OLIVEIRA, Romualdo Portela. A Qualidade do ensino como parte do Direito à Educação: um debate em torno dos indicadores. [texto apresentado à banca de concurso para titular na Feusp]. São Paulo: Faculdade de Educação - USP, 2010. (mimeo)

OLIVEIRA, Sofia Lerche. Educação básica no Ceará: construindo um pacto colaborativo. In: OLIVEIRA, Romualdo Portela; SANTANA, Wagner (Org.). Educação e federalismo no Brasil: combater as desigualdades, garantir a diversidade. Brasília: Unesco, 2010. p. 271-286.

PENSE! Fortaleza, Secretaria de Estado da Educação do Ceará, n.1, jun-jul de 2009. Disponível em 〈 http://pensepaic.seduc.ce.gov.br/?p=149〉. Acesso em: 12 out. 2011.

UNICEF (Brasil). Situação da infância e da adolescência brasileira 2009: 0 direito de aprender: potencializar avanços e reduzir desigualdades. Brasília: Unicef, 2009.

\section{LEIS E DECRETOS}

CEARÁ. Decreto no 29.306/2008 (Dispõe sobre os critérios de apuração dos índices percentuais destinados à entrega de 25\% do ICMS pertencente aos municípios).

CEARÁ. Decreto no 29.896/2009 (Regulamenta a Lei no 14.371/2009, que cria o Prêmio Escola Nota Dez, destinado a premiar as escolas públicas com melhor resultado no Índice de Desempenho Escolar-Alfabetização, IDE-Alfa, e dá outras providências).

CEARÁ. Lei no 14.026/2007 (Cria o Programa Alfabetização na Idade Certa - Paic).

CEARÁ. Lei no 14.371/2009 (Cria o Prêmio Escola Nota Dez, destinado a premiar as escolas públicas com melhor resultado no Índice de Desempenho Escolar-Alfabetização - IDE-Alfa, e dá outras providências).

CEARÁ. Lei no 14.580/2009 (Altera dispositivos da Lei nํㅜ 14.371/2009).

CEARÁ. Regulamenta a Lei no 14.371/2009, que cria o Prêmio Escola Nota 
Dez, destinado a premiar as escolas públicas com melhor resultado no Índice de Desempenho Escolar-Alfabetização, IDE-Alfa, e dá outras providências.

CÂMARA DOS DEPUTADOS. Projeto de lei nํ 8.035/2010. Aprova o Plano Nacional da Educação e dá outras providências.

\section{OUtRos documentos do PAIC}

ANDRADE, Amália Simonetti. Caderno de atividades. Fortaleza: Seduc, 2008. $256 \mathrm{p}$.

ANDRADE, Amália Simonetti. Proposta didática para alfabetizar letrando. 3. ed. rev. amp. Fortaleza: Seduc, 2009. 248 p.

CEARÁ. Secretaria da Educação. Boletim do sistema de avaliação Spaece 2009. Fortaleza: Seduc/UFJF - Caed, 2009. 21 p.

CEARÁ. Eixo de avaliação externa. Fortaleza: Seduc, 2010, 28 p. (mimeo)

CEARÁ. Manual de orientação para o acompanhamento das ações do Paic: município. Fortaleza: Seduc, 2009, 69 p.

CEARÁ. Manual de orientação para o acompanhamento das ações do Paic: regional. Fortaleza: Seduc, 2009, 99 p.

CEARÁ. Manual de orientações para elaboração, execução e prestação de contas dos planos de aplicação de recursos financeiros do Prêmio Escola Nota Dez. Fortaleza: Seduc, 2009, 63 p. (mimeo)

CEARÁ. O Eixo de Literatura Infantil e Formação de Leitores. Fortaleza: Seduc, 2010, 4 p. (mimeo)

CEARÁ. Paic relatório final gestão 2007/2008. Fortaleza: Seduc, 2009, 9 p. (mimeo)

CEARÁ. Plano de trabalho para execução do Programa Alfabetização na Idade Certa. Fortaleza: Seduc, 2007, 46 p. (mimeo)

CEARÁ. Relatório geral de resultados do estado do Ceará: provinha Paic 3ํ, 4ํㅜㄴ e 5a anos - 2010. Fortaleza: Seduc, 2010. 21 p.

Recebido em: OUTUBRO de 2011

Aprovado em: DEZEMBRO de 2011 